Michal Jambor - Frantisek Novy - Milos Mician - Libor Trsko - Otakar Bokuvka - Filip Pastorek

Daniel Harmaniak*

\title{
GAS METAL ARC WELDING OF THERMO-MECHANICALLY CONTROLLED PROCESSED S960MC STEEL THIN SHEETS WITH DIFFERENT WELDING PARAMETERS
}

In this paper are presented results of mechanical properties evaluation of the thin sheets welds made of the S960MC TMCP steel, which were executed using the GMAW procedure with different process parameters. The microstructural changes in the heat affected zone (HAZ) were evaluated, as well. The microstructural observation revealed significant changes in the HAZ and the three main zones, coarse grain, fine grain and intercritical (CGHAZ, FGHAZ and ICHAZ) were identified in the HAZ for both sets of tested welding parameters. Evaluation of the micro-hardness showed significant reduction of the micro-hardness in the ICHAZ, for both tested states, and the ICHAZ was identified as the most critical area of the whole welded joint. Results of the tensile tests revealed significant reduction of mechanical properties regardless of the welding parameters.

Keywords: gas metal arc welding, S960MC steel, heat affected zone, mechanical properties, microstructural changes

\section{Introduction}

The thermo-mechanically controlled processed (TMCP) steels belong to the group of ultra-high strength steels, which exhibit exceptional combination of high tensile and yield strength, toughness and ductility. The ultra-high strength steels exhibit also high abrasion resistance, when comparing to the carbon steels [1]. These properties are obtained by the combination of alloying by small addition of $\mathrm{V}, \mathrm{Ti}, \mathrm{Cr}, \mathrm{Ni}, \mathrm{Si}, \mathrm{Mn}, \mathrm{Mo}$, and properly chosen processing, which allows to achieve the high strength properties while the amount of $\mathrm{C}$ is maintained low [2]. Nowadays, in the many industrial applications, the usage of the high strength steels is increasing [3]. Those steels were introduced in the heavy machinery constructions as heavy mobile cranes, where exist requirements for the high UTS with combination with the high damage tolerance [4], [5], [6], [7]. Exceptional properties led to expansion to other applications like the construction of military vehicles, offshore constructions, shipbuilding industry, high pressure pipes for oil/gas transportation and nowadays also to a construction of commercial vehicles [1], [7], [8], [9]. The only drawback that prevented the wider introducing of the high strength steels to constructions is the higher price of those steels; thus their price must be compensated by introducing other advantages [10]. Application of the high strength steels in constructions enables application of small thickness profiles and consequently reduction of the construction mass [11]. The weight savings in the construction, reached by the substitute of standard mill steels (S355) by the high strength steel S960MC, can be up to $60 \%$ [12]. Efforts to decrease the air pollution is another strong reason to introduce the high strength steels to the construction of transport vehicles, where the reduction of the weight can bring really significant increase of the fuel efficiency and thus the lower the air pollution level [10], [13].

The high strength steels have worse forming properties than conventional mild steels, so their usage in the constructions is restricted to the profiles, which can be easily fabricated (mostly sheets); thus for manufacturing more complicated shapes, welding is the most common technology, which can be used for producing joints of these steels. Using the high strength steels in the construction leads to reduction of the cross section, which also reduces the time required for the welding and the consumption of the filler metal [14]. The high tensile and yield strength of this type of steels is obtained by the combination of the chemical composition, heat treatment and the processing. The heat input into the material during the welding can thus significantly affect properties of the steel and the whole joint. The main problem of the welded structures of high strength steels is the softening in the heat affected zone (HAZ) [8], [15], [16], [17], [18], [19]. In steels with the tensile strength higher than $500 \mathrm{MPa}$, due to the heat effect, occur structural changes in the HAZ, which can significantly degrade properties in those areas [20]. To allow weldability of these steels, without excessive degradation of the mechanical properties, the chemical composition is carefully arranged to meet the requirement for the high mechanical properties with high toughness and to ensure weldability and the resistance to formation of hot and cold cracks [6], [14], [21].

The majority of the recent papers, regarding welding of the high strength steels (especially S960), investigate the effect of the processing parameters and technology on the resulting properties, but those studies mostly consider the quenched-tempered steels and sheets with thickness of $8 \mathrm{~mm}$ and more. It is well known that the welding of the thin sheets can reveal some differences

\footnotetext{
* ${ }^{1}$ Michal Jambor, ${ }^{1}$ Frantisek Novy, ${ }^{2}$ Milos Mician, ${ }^{3}$ Libor Trsko, ${ }^{1}$ Otakar Bokuvka, ${ }^{3}$ Filip Pastorek, ${ }^{2}$ Daniel Harmaniak ${ }^{1}$ Department of Materials Engineering, Faculty of Mechanical Engineering, University of Zilina, Slovak Republic ${ }^{2}$ Department of Technological Engineering, Faculty of Mechanical Engineering, University of Zilina, Slovak Republic ${ }^{3}$ Research Centre, University of Zilina, Slovak Republic

E-mail: michal.jambor@fstroj.uniza.sk
} 
Table 1 Chemical composition (in weight \%) and the mechanical properties of tested material

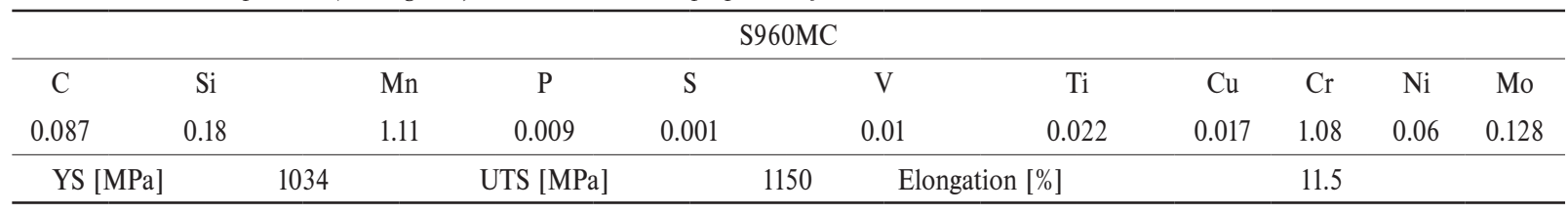

Table 2 Welding parameters used in the study

\begin{tabular}{ccccc}
\hline Weld & Voltage [V] & Current [A] & $\begin{array}{c}\text { Welding speed } \\
{[\mathrm{m} / \mathrm{min}]}\end{array}$ & $\begin{array}{c}\text { Wire feeding rate } \\
{[\mathrm{m} / \mathrm{min}]}\end{array}$ \\
\hline A & 19 & 135 & 0.45 & 4 \\
B & 17 & 120 & 0.23 & 4 \\
\hline
\end{tabular}

Table 3 Chemical composition (in weight \%) and mechanical properties of the filler metal

\begin{tabular}{|c|c|c|c|c|c|c|c|c|c|c|c|c|}
\hline \multicolumn{13}{|c|}{ G 895 M21 Mn4Ni2.5CrMo } \\
\hline $\mathrm{C}$ & $\mathrm{Si}$ & $\mathrm{Mn}$ & $\mathrm{P}$ & $\mathrm{S}$ & $\mathrm{Cr}$ & $\mathrm{Ni}$ & Mo & $\mathrm{Cu}$ & $\mathrm{Al}$ & V & $\mathrm{Ti}$ & $\mathrm{Zr}$ \\
\hline 0.11 & 0.66 & 1.77 & 0.009 & 0.007 & 0.41 & 2.43 & 0.46 & 0.17 & 0.007 & 0.007 & 0.069 & 0.0019 \\
\hline \multicolumn{3}{|c|}{ YS [MPa] } & \multicolumn{2}{|c|}{$\geq 930$} & \multicolumn{2}{|c|}{ UTS [MPa] } & \multicolumn{2}{|c|}{$\geq 980$} & \multicolumn{2}{|c|}{ Elongation [\%] } & \multicolumn{2}{|c|}{$\geq 14$} \\
\hline
\end{tabular}

in the resulting properties of the welded joint when compared to the thick sheets. In this study, the high strength TMCP S960MC steel welded joints were examined. Welded joints prepared from $3 \mathrm{~mm}$ thick sheets were obtained by welding with different welding parameters resulting in different heat input to the material.

\section{Material and experimental procedures}

In this study, the S960MC thermo-mechanically processed steel sheets were used. The chemical composition and the basic mechanical properties of tested steel are shown in Table 1 and they meet the requirements for the S960MC steel according to standard EN 10149-2. Sheets with dimensions $300 \times 300 \mathrm{~mm}$ and thickness of $3 \mathrm{~mm}$ were used. A configuration of the but welded joint without grooves was prepared by a single pass gas metal arc welding (GMAW) technique (gap width was of $1.5 \mathrm{~mm}$, Figure 1). Prior to the welding process, the surface was ground and degreased by ethanol, to prevent occurrence of welding defects. To protect the mold welding pool, prevent the excessive oxidation and obtain adequate penetration, the weld was protected by M21 gas mixture $\left(82 \% \mathrm{Ar}+18 \% \mathrm{CO}_{2}\right)$. Two sets of welding parameters were used; they are shown in Table 2. The G 895 M21 Mn4Ni2.5CrMo filler metal (EN ISO 16834-A) in the form of a wire with $\phi=1 \mathrm{~mm}$ was used. Chemical composition and mechanical properties of used welding wire are shown in Table 3 . The welds were obtained without any preheating and with cooling in the air. No additional post-weld heat treatment was applied.

After the welding procedure, the specimens were cut in the transversal direction. The tensile tests were carried out, according to EN ISO 6892-1 standard to obtain the mechanical properties of the weldments. Specimens for the tensile tests were prepared according to EN ISO 4136 standard. Two specimens from the both welds were manufactured.

The microstructure evolution after the welding was characterized by the optical microscopy; specimens were prepared by the standard procedure for preparation of metallographic specimens and etched by $1 \%$ Nital. Specimens for macroscopic

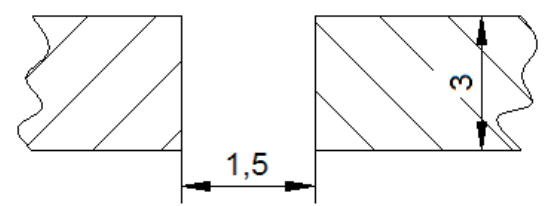

Figure 1 Schematic view of the welding configuration.

and microscopic evaluation and the microhardness measurements were cut from the sheets at the minimal distance $25 \mathrm{~mm}$ from the begining of the welds. Microhardness measurements were used for characterization of changes of the properties through the welds; the microhardness was measured in the line, from the base metal, through the weld up to the base metal on the other side. For all the micro-hardness measurements, the force $F=1 \mathrm{kp}(9.8$ N) was used.

\section{Results and discussion}

\subsection{Macro and microstructural characterization}

Welds were prepared with the two different sets of welding parameters. The most significant differences were in the welding speed, which resulted in the $60 \%$ increase of the heat input in the second weld. For simplification, the weld made with the lower heat input will be designated as 'weld A' and the other one as a 'weld B'. Both welded sheets were subjected to visual control, which did not reveal presence of any defects on the welds surface and there were none visual differences between both welds, as well. The welds'geometry was macroscopically examined (Figure 2a, Figure 2b) and it fulfills requirements according to EN ISO 17639 standard for the used type of welds. As a result of macroscopic observation, it was found that both tested joints have no cracks, no lack of penetration, no porosity, regular profile and a smooth transition to the base metal. A small angular deviation was observed, as a result of the welding process during which the sheets were not clamped. Despite the large 

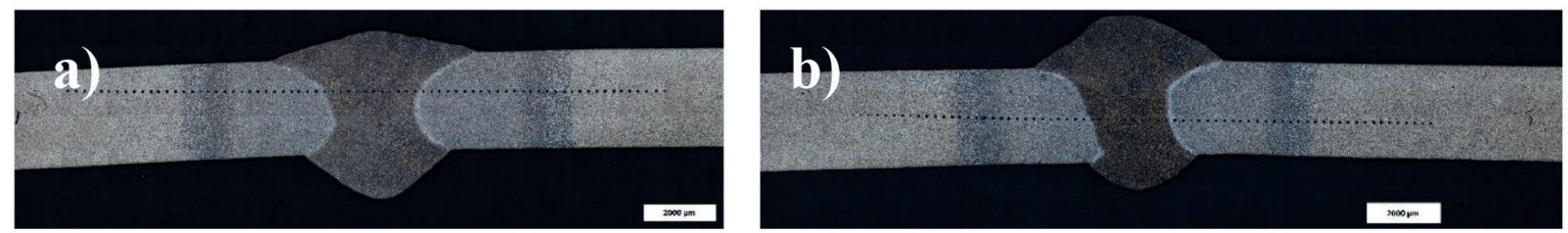

Figure 2 Macroscopic view of the weld $A(a)$ and weld B (b)

differences in the heat input, no enlargement of the HAZ due to the higher heat input was observed. Due to the low thickness of the welded sheets, most of the heat is transferred rapidly to the air, and no excessive heat dissipation in the welded sheets occurs. As a result, the higher heat input does not significantly enlarge an area which is heated above the $\mathrm{A}_{\mathrm{C} 1}$ temperature. The greater emphasis was placed on the microstructural observation. Microstructure of the base metal is shown in Figure 3 and it is composed of a mixture of martensite and tempered martensite. This kind of structure allows obtaining the combination of high mechanical properties and high toughness. The weld metal (WM) microstructure was characterized as a mixture of martensite and tempered martensite in the large columnar grain structure (Figure 4). No significant differences were recorded in the comparison of welds A and B. The heat affected zone (HAZ) is the most problematic zone in the welds of the high strengths steels, as its properties are a result of the thermo-mechanical processing; introducing of the thermal energy during the welding process can significantly affect the structure in the HAZ and thus also the resulting properties of the whole weldedjoint. Regardless of the welding parameters, three different areas in the HAZ, were recorded, depending on the temperature to which the individual zones were exposed and the cooling rates (the similar behavior was reported by many authors [2], [9], [12], [14]). In the direction from the weld metal to the base metal, the first observed zone was the coarse grain zone (CGHAZ) (Figure 5a, Figure $5 b)$. The CGHAZ is the area, which was heated high above the $A_{c 3}$ temperature, what resulted in the transformation of the base metal to austenite, which subsequently grew. Followed by the rapid cooling, the enlarged austenitic grains transformed back to martensite. The amount of the austenite phase growth increases with getting closer to the fusion zone, which corresponds to the temperature increase in the same direction. Coarsening of the austenitic grains in the TMCP steels at elevated temperatures is accelerated by the dissolving of $\mathrm{NbC}$ (and other small particles) in the matrix, and thus the pinning effect is significantly reduced [22]. The second area resolved in HAZ, is the fine grain heat affected zone (FGHAZ) (Figure 5c, Figure 5d). This area was heated slightly above the $A_{c 3}$ temperature, but the holding time above $A_{c 3}$ was very short. Exposure to heat at this zone caused thetransformation of the base metal to austenite, but due to the low temperature and very short duration of this exposure, followed by the rapid cooling, it resulted in the refinement of austenitic structure and its subsequent transformation to martensite. The last area of the HAZ is called the intercritical heat affected zone (ICHAZ) (Figure 5e, Figure 5f). This area was exposed to temperatures in the range between $A_{c 1}$ and $A_{c 3}$ where the martensite is partially transformed to austenite. This exposure resulted in formation of the mixture of martensite and austenite, which transformed, after the rapid cooling, to martensite and

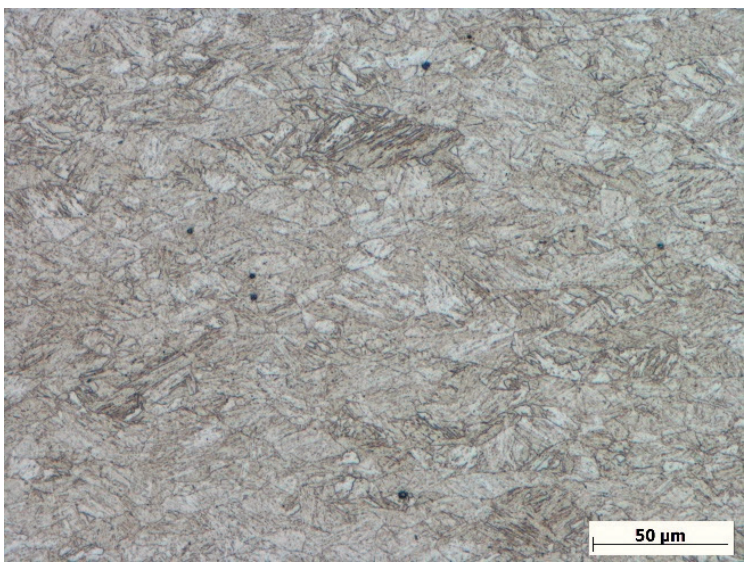

Figure 3 Microstructure of the base metal

ferrite, while the untransformed martensite was tempered. The resulting microstructure of this area is the mixture of martensite, ferrite and tempered martensite - similar to other studies [9], [12]. According to other authors, the ICHAZ is the weakest area in the welded quenched-tempered and TMCP steels [1]. The width of the ICHAZ was approximately $740 \mu \mathrm{m}$ for weld A and slightly less for the weld B - approximately $680 \mu \mathrm{m}$, but it is unlikely, that this difference could be significant for the mechanical properties of the whole welded joint. In addition, the base metal near the HAZ was affected by the introduced heat, but heat exposure did not exceed the $A_{c 1}$ temperature, so no phase transformation occured, only a tempering of the martensite phase, which actually resulted in decrease of the mechanical properties in that area.

\subsection{Microhardness measurements}

Phase transformations occurred mainly in the HAZ and strongly affected the resulting mechanical properties of the whole welds. Microhardness measurements were performed by the measuring hardness profiles from the base metal, throughout the HAZs and the weld metal (WM). The microhardness profiles are shown in Figure 6.

Microhardness profiles show continual decrease of microhardness in the direction from the base metal to ICHAZ, which was similar for both welds. This decrease is related to the tempering of martensite in the base metal structure. Decrease of strength related properties is common behavior for all the high strength steels (quenched tempered and TMCP steels), when they are heated in the range $450{ }^{\circ} \mathrm{C}-\mathrm{A}_{\mathrm{cl}}$ temperature, due to martensite tempering [5]. The lowest values of microhardness were obtained in the ICHAZ, where only $66 \%$ of the base metal hardness was recorded. The ICHAZs seems to be most critical areas, even the width of these zones is relatively small $(\approx 0.7 \mathrm{~mm})$. 

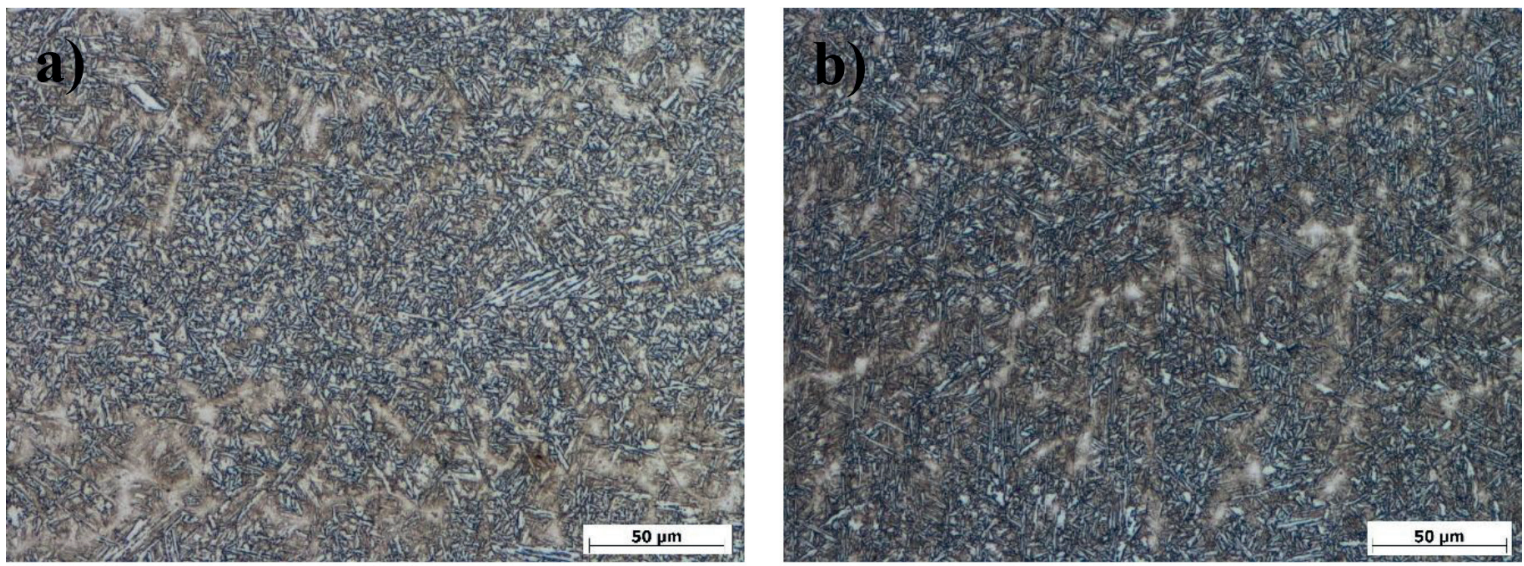

Figure 4 Microstructures of the weld metal, weld $A(a)$ and weld B (b)
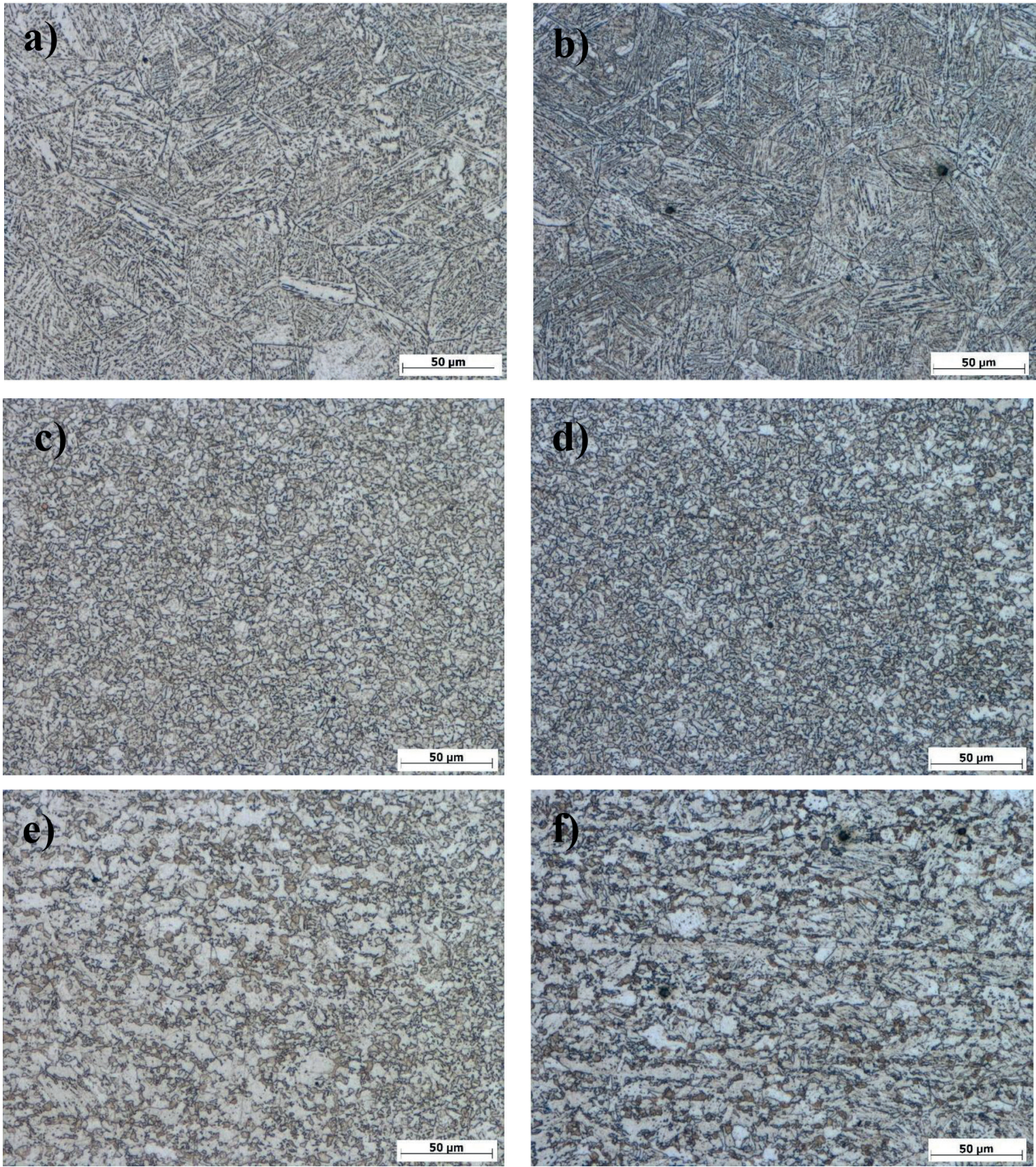

Figure 5 Microstructures of the HAZ; $a, c$ and e represent CGHAZ, FGHAZ, ICHAZ of weld A, respectively; $b, d$ and $f$ represent CGHAZ, FGHAZ and ICHAZ of weld $B$, respectively 
Microhardness evolution in the weld joints

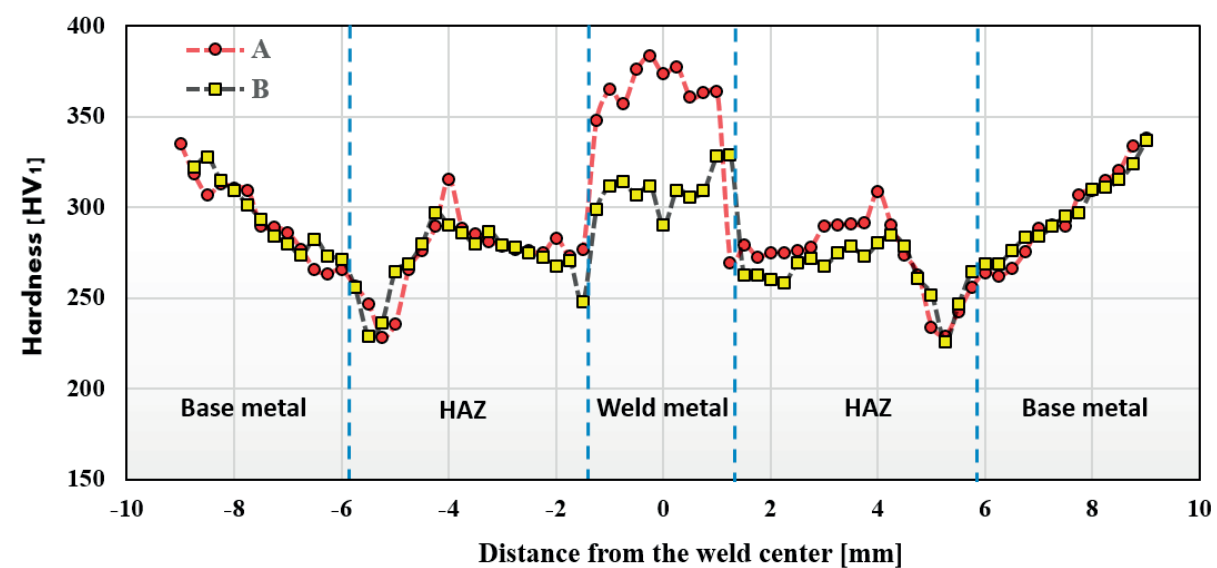

Figure 6 Micro-hardness profile of the welds

Table 4 Results of the welds tensile tests

\begin{tabular}{cccc}
\hline & YS [MPa] & UTS [MPa] & Elongation [\%] \\
\hline A-01 & 794 & 826 & 5 \\
A-02 & 836 & 858 & 3 \\
Average - weld A & 815 & 842 & 3 \\
B-01 & 830 & 848 & 3 \\
B-02 & 838 & 877 & 3 \\
Average - weld B & 834 & 863 & 11.5 \\
Base metal & 1034 & 1150 & \\
\hline
\end{tabular}

In FGHAZ, the microhardness started to increase and reached its maximum at microstructures shownin Figure 2c, Figure 2d. For the weld $\mathrm{A}$, the maximum value was a little bit higher than for the weld $\mathrm{B}$, which is related to the amount of heat introduced to the material during the welding. Towards the CGHAZ, a small decrease of microhardness was recorded, what is related tothe excessive grain growth in this zone. The microhardness in that area is given by the mean grain size, which is a function of the cooling rate and the holding time at elevated temperatures [22]. The weld metal microhardness values were different for the two welds. Weld A exhibits the higher microhardness in the weld metal, value of $383 \mathrm{HV}$, was recorded. Though this value is higher than that of the base metal, it is still lower than the considered limit value $450 \mathrm{HV}$, at which an embrittlement of the welded joint can occur. The weld metal in the weld B exhibited the lower microhardness, the maximum value recorded in that area was 328 $\mathrm{HV}_{1}$. According to that, the higher heat input used in the weld $B$ resulted in the lower hardness of the weld metal. In majority of cases, achieving of lower microhardness values in the weld metal is desirable, but in this case, these values were even lower than the base metal microhardness, thus it could be detrimental for the whole welded joint properties. Some authors suggest that the main problem during the welding of the high strength steels is an increasing hardness in the weld metal region, which causes embrittlement and lower toughness and ductility. In this study, the highest measured hardness in the weld metal region was only 383 $\mathrm{HV}_{1}$ for weld A and $328 \mathrm{HV}_{1}$ for weld $\mathrm{B}$. According to previously mentioned values, the most crucial for theTMCP steels is not an increase of the mechanical properties in the weld metal region but a decrease of the mechanical properties in the HAZ. This is in consistence with other authors, but in the case of thin sheet, the HAZ softening is more dramatic. The sheets with the lower thickness are more susceptible to excessive overheating and thus the degradation of the properties in HAZ is more likely to occur. Depending on the width of that HAZ, the general properties of thewelded joint can be decreased. The TMCP steels are more susceptible to the HAZ softening than thequenched-tempered steels with the similar mechanical properties, sincetheir carbon content is lower and the final mechanical properties are reachedby several strengthening mechanisms. (Precipitates of-V,Nb,Ti-CN, which can dissolve in the matrix at high temperature exposures, also influence the high mechanical properties,which can contribute to the strength reduction after the welding) [6].

\subsection{Tensile tests}

The tensile tests were performed according to EN ISO 6892-1 standard and two specimens of each weld were tested. Results of the tensile tests are shown in Table 4.

The tensile tests show the significant reduction of the tensile strength and yield strength. The ultimate tensile strength was reduced to $79 \%$ of the base metal value in the weld $\mathrm{A}$ and $81 \%$ in the weld B. Similarly, the yield strength was reduced as well, and it reached $73 \%$ of the base metal yield strength in the weld $\mathrm{A}$, and $75 \%$ in the weld $\mathrm{B}$. Regardless of welding parameters, the UTS and YS were significantly reduced in both welds. Even more dramatic decrease was recorded for the 
tensile elongation. The tensile elongation reduction was similar in both welds and its value reached less than $40 \%$ of the parent base material elongation. Fracture of specimens, tested by the tensile tests, occurred approximately $6 \mathrm{~mm}$ from the weld center in all thespecimens, what corresponds to the micro-hardness measurements and appearance of the most softened zone in that area. Thus, it can be said that the fracture occurs in the narrow area of the ICHAZ. This phenomenon is a result of changes in the ICHAZ microstructure, where the softening occurs in the narrow areas. Due to the decrease of the yield strength of these regions, the plastic deformation during the tensile testing occurs in these regions at lower stress values than the yield strength of the rest of the weld; thus the yielding occurs only in those narrow areas, which results in localization of all the plastic deformation to relatively small area causing the significant reduction of the tensile elongation. Some authors claim that the decrease of the ductility and toughness is a result of formation of the brittle martensite phases in the HAZ (especially in the CGHAZ) [22], [23], but according to result of the tensile tests, the fracture occurs in the region of ICHAZ and the reduction of tensile elongation is due to yielding localization. In the study [12], the $8 \mathrm{~mm}$ thick S960QL steel sheets were successfully welded by the multi pass GMAW technique, with the heat input ranging from $4.6 \mathrm{~kJ} / \mathrm{cm}$ to $8.4 \mathrm{~kJ} / \mathrm{cm}$. A decrease of hardness in the HAZ was also recorded, but the decrease was only $15 \%$ and result of the tensile tests showed the $7.1 \%$ drop in the UTS and $1.4 \%$ drop in elongation. The failure of the tensile specimens also occurred in the HAZ. There are many other studies where the high strength steels were successfully welded by using the GMAW with the heat input of 7-18 kJ/cm [5], [8], [12], but those studies were carried on much thicker sheets (at least $8 \mathrm{~mm}$ ) and, in addition, the used steels were mostly of the quenched-tempered type, which has the higher carbon content. Based on the previously mentioned facts, there follow a few important conclusions. At first, the changing of welding parameters (in the range used in this study: 2.3-4.3 $\mathrm{kJ} / \mathrm{cm}$ ) did not significantly affect the overall properties of the welded joints. The weld made with the higher heat input showed the better mechanical properties, though the lower values of microhardness were recorded in the HAZ and WM. Comparison of those results to other studies, made on quenched tempered steels, shows that there is clearly an evident higher drop of the mechanical properties for the TMCP steels, which contain less carbon and the high mechanical properties are also obtained by other strengthening mechanisms. The last very important factor is the thickness of the welded sheets. Sheets of a smaller thickness are more susceptible to excessive overheating and thus the degradation of the properties in the HAZ is more likely to occur, which results in the severe degradation of the overall properties of whole joint.

\section{Conclusions}

Based on the carried out experiments, the following conclusions can be drawn:

- The S960MC TMCP steels sheets of $3 \mathrm{~mm}$ thickness were successfully welded with the G $895 \mathrm{M} 21 \mathrm{Mn} 4 \mathrm{Ni} 2.5 \mathrm{CrMo}$ filler metal without appearance of any cracks and weld imperfections.

- The microstructure observations revealed a few different zones in the HAZ, whose evolution was similar for the both sets of welding parameters and only minor differences were recorded as a result of difference in welding parameters.

- The microhardness measurement shows that the ICHAZ is the weakest area of the whole joint, with microhardness of only $66 \%$ of the parent material hardness. Similar values were recorded for both sets of tested welding parameters and no correlation between the ICHAZ microhardness and the heat input was found.

- The weld metal microhardness was found to be dependent on the welding parameters. In the weld A, the hardness exceeds hardness of the base metal, but that value still did not exceed $400 \mathrm{HV}_{1}$; thus there are no concerns for any embrittlement. The weld metal in the weld B exhibits the lower hardness than the base metal, due to excessive heat input.

- The tensile tests show the significant reduction of mechanical properties and elongation for both tested welds, where the YS reached $73 \%$ of that of the base metal, the UTS reached $79 \%$ and elongation less than $40 \%$ of the base metal values.

- No significant differences were found in the welds properties after welding with the heat inputs of 2.7 and $4.3 \mathrm{~kJ} / \mathrm{cm}$, while the slightly higher mechanical properties were obtained with the latter one.

- Thin sheets of the TMCP steels are strongly susceptible to excessive overheating, so the standard GMAW procedure is not an appropriate method for welding the thin sheets made of the TMCP S960MC steel. Modern welding methods using high energy narrow beams (electron/laser) could be the solution to the problem of TMCP thin sheets welding.

\section{Acknowledgement:}

The research was supported by Scientific Grant Agency of the Ministry of Education, Science, Research and Sport of the Slovak Republic under the contract VEGA No. 1/0951/17 and Slovak Research and Development Agency under the contract no. APVV-16-0276 and APVV-14-0096.

\section{References}

[1] SHARMA, V., SHAHI, A. S.: Quenched and Tempered Steels Welded with Micro-Alloyed Based Ferritic Fillers. Journal of Materials Processing Technology, 253, 2-16. 2018. https://doi.org/10.1016/j.jmatprotec.2017.10.039

[2] BLACHA, S., WEGLOWSKI, M. S., DYMEK, S., KOPYSCIANSKI, M.: Microstructural and Mechanical Characterization of Electron Beam Welded Joints of High Strength S960QL and Weldox 1300 Steel Grades. Archives of Metallurgy and Materials, 62(2A), 627-634, 2017. https://doi.org/10.1515/amm-2017-0092 
[3] BORKO, K., HADZIMA, B., NESLUSAN-JACKOVA, M.: Corrosion Resistance of Domex 700 Steel after Combined Surface Treatment in Chloride Environment. Procedia Engineering, 192, 58-63, 2017. https://doi.org/10.1016/j.proeng.2017.06.010

[4] GOSH, M., KUMAR, K., MISHRA, R. S.: Analysis of Microstructural Evolution during Friction Stir Welding of UltrahighStrength Steel. Scripta Materialia, 63, 851-854, 2010. http://dx.doi.org/10.1016/j.scriptamat.2010.06.032

[5] GASPAR, M., BALOGH, A.: GMAW Experiments for Advanced (Q+T) High Strength Steels. Production Processes and Systems, 6, 9-24, 2013.

[6] WEGLOWSKI, M. S., ZEMAN, M.: Prevention of Cold Cracking in Ultra-High Strength Steel Weldox 1300. Archives of Civil and Mechanical Engineering, 14(3), 417-424, 2014. https://doi.org/10.1016/j.acme.2013.10.010

[7] NEIMITZ, A., DZIOBA, I., LIMNELL, T.: Modified Master Curve of Ultra High Strength Steel. International Journal of Pressure Vessels and Piping, 92, 19-26, 2012. https://doi.org/10.1016/j.jpvp.2012.01.008

[8] MIN, D., XIN-HUA, T., FENG-GUI, L., SHUN, Y.: Welding of Quenched and Tempered Steels with High-Spin Are Narrow Gap MAG System. The International Journal of Advanced Manufacturing Technology, 55(5-8), 527-533, 2011.

[9] GUO, W., CROWTHER, D., FRANCIS, J. A., THOMPSON, A., LIU, Z., LI, L.: Microstructure and Mechanical Properties of Laser Welded S960 High Strength Steel. Materials and Design, 85, 534-548, 2015. https://doi.org/10.1016/j.matdes.2015.07.037

[10] SENUMA, T.: Physical Metallurgy of Modern High Strength Steel Sheets. ISIJ International, 41(6), 520-532, 2001.

[11] ARSIC, D., LAZIC, V., NIKOLIC, R., ALEKSANDROVIC, S., HADZIMA, B., DJORDJEVIC M.: Optimal Welding Technology of High Strength Steel S690QL. Materials Engineering - Materialove Inzinierstvo, 22, 33-47, 2015.

[12] GUO, W., LI, L., DONG, S., CROWTHER, D., THOMPSON, A.: Comparison of Microstructure and Mechanical Properties of Ultra-Narrow Gap Laser and Gas-Meta-Arc Welded S960 High Strength Steel. Optics and Lasers in Engineering, 91, 1-15, 2017. https://doi.org/10.1016/j.optlaseng.2016.11.011

[13] YOUN - SUK, J., YOUNG-KOOK, L., DONG-CHEOL, K., MOON-JIN, K., IN-SUNG, H., WON-BEOM, L.: Microstructural Evolution and Mechanical properties of Resistance Spot Welded Ultra High Strength Steel Containing Boron. Materials Transactions, 52(6), 1330-1333, 2011. https://doi.org/10.2320/matertrans.M2011005

[14] NOWACKI, J., SAJEK, A., MATKOWSKI, P.: The Influence of Welding Heat Input on the Microstructure of Joints of S1100QL Steel in One Pass Welding. Archives of Civil and Mechanical Engineering, 16, 777-783, 2016. https://doi.org/10.1016/j. acme.2016.05.001

[15] VALKONEN, I.: Ultimate Limit Load in Welded Joints and in Net Section of High Strength Steels with Yield Stress 960 MPa. Procedia Materials Science, 3, 720-725, 2014. https://doi.org/10.1016/j.mspro.2014.06.118

[16] LAZIC, V., ALEKSANDROVIC, S., ARSIC, D., SEDMAK, A., ILIC, A., DJORDJEVIC, M., IVANOVIC, L.: The Influence of Temperature on Mechanical Properties of the Base Metal (BM) and Welded Joint (WJ) Made of Steel S690QL. Metalurgija, 55(2), 213-216, 2016.

[17] QIANG, X., JIANG, X., BIJLAARD, F. S. K., KOLSTEIN, H.: Mechanical Properties and Design Recommendation of Very High Strength Steel S960 in Fire. Engineering Structures, 112, 60-70, 2016. https://doi.org/10.1186/s40038-017-0017-6

[18] TALAS, S.: The Assessment of Carbon Equivalent Formulas in Prediction the Properties of Steel Weld Metals. Materials and Design, 31, 2649-2653, 2010. https://doi.org/10.1016/j.matdes.2009.11.066

[19] OYYARAVELU, R., KUPPAN, P., ARIVAZHAGAN, N.: Metallurgical and Mechanical Properties of Laser Welded High Strength Low Alloy Steel. Journal of Advanced Research, 7, 463-472, 2016. https://doi.org/10.1016/j.jare.2016.03.005

[20] BARSOUM, Z., KHURSHID, M.: Ultimate Strength Capacity of Welded Joints in High Strength Steels. Procedia Structural Integrity, 5, 1401-1408, 2017. https://doi.org/10.1016/j.prostr.2017.07.204

[21] MAZUR, M., ULEWICZ, R., NOVY, F., SZATANIAK, P.: The Structure and Mechanical Properties of DOMEX 700 MC Steel. Communications - Scientific Letters of the University of Zilina, 31(4), 54-57, 2013.

[22] LAN, L., QIU, CH., ZHAO, D., GAO, X., DU, L.: Microstructural Characteristics and Toughness of Simulated Coarse Grained Heat Affected Zone of High Strength Low Carbon Bainitic Steel. Material Science and Engineering A, 529, 192-200, 2011. https:// doi.org/10.1016/j.msea.2011.09.017

[23] LAN, L., QIU, CH., ZHAO, D., GAO, X., DU, L.: Analysis of Microstructural Variation and Mechanical Behaviors in Submerged Arc Welded Joint of High Strength Low Carbon Bainitic Steel. Material Science and Engineering A, 558, 592-601, 2012. https:// doi.org/10.1016/j.msea.2012.08.057 